\title{
Superando a crise na teoria do currículo: uma abordagem baseada no conhecimento ${ }^{123}$
}

Michael Young

Professor do Instituto de Educação da Universidade de Londres

E-mail:m.young@ioe.ac.uk
Resumo: Este artigo começa por identificar o que o autor vê como a atual crise na teoria do currículo. Após uma breve história desta área, pondera-se que recentes acontecimentos levaram-na a perder seu foco - o que é ensinado e aprendido na escola - e seu papel específico nas Ciências da Educação. Deste breve relato sobre as origens e a natureza dessa "crise", o autor informa que a teoria do currículo não deve partir do aprendiz, mas sim do direito do aluno ao conhecimento. Em seguida, desenvolve um modelo teórico para abordar o currículo com base nessa premissa, que é ilustrado pelo exemplo da diretora de uma grande escola secundária na Inglaterra, que usou estas ideias. Finalmente, examina três críticas recorrentes à abordagem curricular baseada no conhecimento e as questões levantadas por elas.

Palavras-chave: Currículo. Conhecimento. Especialização. Disciplinas.

Tradução de Leda Beck e revisão técnica de Paula Louzano.

Este artigo foi publicado originalmente na revista J. Curriculum Studies, v. 45, n. 2 p. 101-118, abr. 2013. Os direitos autorais foram adquiridos junto aos editores. 0 original está disponível em: 〈http://dx.doi.org/10.1080 /00220272.2013.764505〉.

3 Gostaria de agradecer a Lyn Yates por seus comentários numa versão anterior deste artigo e as críticas valiosas de um de meus avaliadores. Agradeço também a Carolyn Roberts pelo texto A Knowledge-Driven School (Uma escola voltada para o conhecimento). 


\section{INTRODUÇÃO}

De quais questões deve tratar uma teoria do currículo? Meu ponto de partida, pelo menos na última década (YOUNG, 2009), tem sido 'o que os alunos têm o direito de aprender, quer estejam numa escola primária ou secundária, frequentando a universidade ou um programa de educação profissional ou vocacional que visa a prepará-los para o mercado de trabalho?’. Essa pergunta não tem uma resposta 'definitiva'; as sociedades mudam, então cada geração precisa fazer essa pergunta novamente - e ela não é fácil. De um lado, como educadores, temos a responsabilidade de entregar à próxima geração o conhecimento acumulado pelas anteriores. É esse elemento de continuidade entre gerações que nos distingue dos animais; é uma maneira de dizer que somos sempre parte da história. Por outro lado, o propósito do currículo, pelo menos nas sociedades modernas, não é apenas transmitir o conhecimento acumulado; também é habilitar a próxima geração para construir sobre esse conhecimento e criar novo conhecimento, pois é assim que as sociedades humanas progridem e os indivíduos se desenvolvem. As sociedades primitivas, que não tinham escolas, permaneceram literalmente inalteradas por séculos. Mas herdamos uma característica importante dessas sociedades e das primeiras sociedades com escolas: embora o conhecimento transmitido por essas primeiras escolas fosse sobretudo religioso (e supostamente fixo), ele era claramente diferente da experiência cotidiana dos alunos. Este artigo voltará a este ponto no contexto contemporâneo.

A interdependência entre os propósitos de 'transmitir o conhecimento acumulado' e 'ser capaz de usar esse conhecimento para criar novo conhecimento', assim como difundir essa habilidade para um número cada vez maior de pessoas em cada geração, levanta problemas de difícil solução para teóricos do currículo, elaboradores de currículo e professores. Para resolver esses problemas, é preciso romper com as duas abordagens predominantes da educação que herdamos do passado ou, pelo menos, promover a ‘superação' delas.

Uma dessas abordagens é característica das tradições europeias, mas tem paralelos nas regiões do mundo que beberam na tradição de Confúcio e, se recuarmos ainda mais na história, também na do Islã. Essa abordagem herda uma visão do currículo como fonte do ‘sagrado’4, que, desde o século XIX, tem

4 Uso o termo ‘sagrado' no sentido mais amplo proposto por Durkheim (1915), que não é limitado à religião, mas se refere a quaisquer significados separados dos problemas da vida cotidiana, como encontrar comida e abrigo. 
sido progressivamente secularizada para formar as áreas do conhecimento na universidade e as disciplinas escolares com alcance global cada vez maior (MEYER, 1992). No entanto, a despeito da expansão massiva, tanto do novo conhecimento como das oportunidades de educação a que essas tradições levaram, elas não conseguiram, pelo menos até agora, tornar-se totalmente democráticas e alcançar a 'educação para todos’. Em consequência, essas tradições têm inspirado críticas e alternativas que rejeitam a ideia do 'sagrado' e confiam não na 'construção do conhecimento sobre o conhecimento', mas nas capacidades inatas de todos os alunos (e, para alguns, de todas as culturas) para construir seu próprio conhecimento. Essa tradição progressista, centrada no aluno, pode ser encontrada desde Rousseau e assumiu sua forma mais sofisticada nos escritos daqueles que foram influenciados por Dewey 5 . Nessa visão, o potencial 'natural’ dos alunos só será alcançado se eles forem libertados do constrangimento de endossar o 'sagrado' e das tradições percebidas como pertencentes inerentemente ao passado. Resultam dessa visão dois modelos em que as possibilidades emancipadoras da educação são muito diferentes. Um deles aposta no conhecimento e, para alguns de seus defensores, também na amplitude inerente ao próprio conhecimento - quanto mais sabemos, mais sabemos quão pouco sabemos. Para essa tradição, os professores não são meros 'facilitadores do aprendizado', mas autoridades pedagógicas no campo em que se tenham especializado. A falha e a vulnerabilidade dessa tradição relacionam-se, por um lado, com as formas cada vez mais especializadas que o conhecimento assume e os limites que isso estabelece no acesso a este conhecimento. Por outro lado, essa tradição tende a esquecer quanto ainda temos a descobrir sobre pedagogia, ela mesma um campo especializado do conhecimento, e quão pouco ainda se investe, relativamente, nessa tarefa.

O segundo modelo aposta nas capacidades emancipadoras dos alunos, se ao menos soubéssemos como colocá-las em prática. Este tem sido massivamente promovido pelo suposto potencial das tecnologias digitais para melhorar a educação, embora, creio, de maneira equivocada. Alguns argumentam que, se os professores permitissem aos alunos o acesso irrestrito à informação disponível na internet, o aprendizado seria a norma para todos e não apenas para poucos. Apesar do poder de persuasão desse argumento, ainda não há evidências de que um recurso informacional - por mais extenso e acessível

Isso não significa que Dewey não tinha consciência das limitações de uma abordagem centrada na criança ou no aluno. Não se pode negar, porém, que foi assim que muitos de seus seguidores o interpretaram (EGAN, 2004) ou que, a despeito do que ele escreveu, sua própria epistemologia pragmática abre espaço para essa crítica (DURKHEIM, 1983). 
que seja - possa, sozinho, promover aprendizado real. 0 erro dessas teorias é usar como modelo a impressionante capacidade que todos têm de aprender de maneira experimental ou informal para uma tarefa bem diferente: superar nossa experiência, uma oportunidade que só escolas e professores podem oferecer.

Sugiro que o desafio da teoria do currículo seja o de transcender esses dois modelos, tomando da tradição do ‘sagrado' não apenas a ideia do 'estoque de conhecimento', mas também os valores tipicamente humanos da introspecção e do compromisso pessoal, que dão forma e são associados ao estudo disciplinado e à investigação sistemática. Em resposta aos críticos da exclusividade do 'sagrado', a teoria do currículo deve argumentar que as disciplinas não são fixas ou dadas, mas têm um propósito - a descoberta da verdade -, a qual está, em princípio, aberta a todos que estão preparados para fazer esse esforço e que são adequadamente apoiados nesse compromisso. Está claro que isso não implica que somente o esforço distingue, nas sociedades de hoje, aqueles que progridem na escola daqueles que não progridem; há enormes fatores políticos definindo a distribuição de oportunidades. Meu argumento é que a grande tarefa da teoria do currículo é identificar as restrições ${ }^{6}$ que limitam as escolhas curriculares e explorar as implicações pedagógicas resultantes de cada uma dessas escolhas.

Até aqui, delineei o que considero o papel da teoria do currículo especificamente em relação à questão do 'acesso ao conhecimento'. Em minha opinião, é um papel que tem sido amplamente negligenciado, por várias razões. Essa negligência é 'a crise' referida no título deste artigo. Isso não significa que a teoria do currículo ou outros campos dos estudos curriculares tenham abandonado a questão do conhecimento (DENG; LUKE, 2008). 0 que digo é que essa 'crise' se expressa na relutância da teoria do currículo, pelo menos desde Hirst e Peters (1970), em abordar temas epistemológicos relacionados às questões da verdade e da confiabilidade das diferentes formas de conhecimento, questões que têm dimensões tanto filosóficas como sociológicas.

Qual é o conhecimento que os alunos deveriam poder adquirir na escola? Se, como teóricos do currículo, não conseguimos responder a esta pergunta, então não está claro quem poderá respondê-la e é provável que a resposta venha de decisões pragmáticas e ideológicas de gestores e políticos.

6 Aqui, concentro-me nos limites epistemológicos de um currículo que habilite os alunos a acessar o que chamarei mais adiante de 'conhecimento poderoso'. 
A seguir, faço uma breve discussão sobre as possíveis razões pelas quais a questão do conhecimento tem sido evitada por estudiosos da teoria do currículo e sugiro como a teoria do currículo poderia partir da questão do conhecimento. Por último, ilustro brevemente como tal abordagem poderia ser aplicada de maneira concreta nas escolas. 0 artigo conclui com uma breve consideração sobre por que a questão do conhecimento tem sido sistematicamente evitada por educadores como um todo e não apenas pelos especialistas em currículo. Este é o caso do Reino Unido, onde os atuais debates sobre conhecimento e currículo têm sido conduzidos quase exclusivamente pelos políticos que estão no poder (YOUNG, 2011), mas essa tendência não está restrita a um único país (YATES; YOUNG, 2010).

\section{AS ORIGENS DOS ESTUDOS CURRICULARES COMO UM CAMPO}

Raymond Callaghan pondera, em seu livro brilhante e pouco conhecido, Education and the Cult of Efficiency (CALLAGHAN, 1964), que a teoria do currículo surgiu inicialmente nos Estados Unidos para resolver problemas enfrentados por diretores de escola. Os primeiros teóricos do currículo, como Bobbitt (1918), que aplicou a 'gerência científica' de F. W. Taylor para melhorar a produtividade em fábricas, tinham certeza de que as lições relacionadas à manufatura podiam ser aplicadas às escolas. O objetivo das escolas - ou, em outras palavras, ‘o que devia ser aprendido’ - não estava em discussão porque estava dado. Portanto, o currículo era interpretado como mera instrução e organização eficiente dos recursos de ensino. Esses primeiros teóricos do currículo e os que os seguiram, como Tyler e Taba, entendiam a instrução de maneira altamente prescritiva. Os primeiros críticos desse modelo foram Apple (2004 [1975]) e Pinar (1978). Juntos, seus primeiros trabalhos transformaram e, literalmente, 'libertaram' o campo da rigidez e da aridez dos modelos associados com Bobbitt, Tyler e Taba.

No Reino Unido, tivemos a sorte de evitar a obsessão estadunidense com a ideia de objetivos instrucionais. No entanto, o conceito de 'educação liberal', associado a escolas 'públicas' pagas como Eton e Harrow, foi igualmente difundido. Do ponto de vista do currículo, o conceito de 'educação liberal' recebeu uma expressão mais formal na Inglaterra com os filósofos Hirst e Peters (1970), cuja formulação foi desafiada, de uma perspectiva explicitamente sociológica, pelo que veio a ser conhecido como 'a nova Sociologia da Educação' (YOUNG, 1971)`.

O trabalho inicial de Bernstein (1971) tinha mais profundidade conceitual e uma influência mais duradoura na teoria do currículo, assim como na Sociologia da Educação. Mas a 
A relevância dessas reflexões dos anos 1970 é que, embora tenham aberto novos caminhos para o campo dos estudos curriculares, levando a várias pesquisas empíricas inovadoras (GOODSON, 1987), elas também politizaram o campo (YOUNG; WHITTY, 1977) e pavimentaram o caminho para sua absorção pela retórica radical da 'pedagogia crítica' que ainda tem muitos seguidores nas faculdades de Educação (GIROUX, 1983; MCLAREN, 1995). A força dessas correntes de teoria crítica do currículo está em explicitar 0 currículo oculto, que incorpora as relações prevalentes de poder. Descrevi isso como uma visão do currículo como 'conhecimento dos poderosos' (YOUNG, 2008). No entanto, por seu foco unidimensional em quem tem o poder para definir o currículo, essa tradição negligenciou o quanto algumas formas de conhecimento dão maior poder do que outras aos que têm acesso a elas, independentemente da origem social dos produtores desse conhecimento. O foco no 'conhecimento dos poderosos', a despeito de seus pontos fortes, quase inevitavelmente desloca a análise daquilo que se passa na escola para o que está ocorrendo com a distribuição de poder na sociedade em geral e oferece pouco aos professores e aos movimentos sociais que buscam uma abordagem mais equitativa do currículo. Essa tradição parte do princípio de que o atual currículo, baseado no 'conhecimento dos poderosos', poderia ser modificado por uma transformação política - mas não oferece nenhuma indicação sobre o que seria o novo currículo. Nos raros momentos históricos em que a esquerda tomou o poder - e em contextos não limitados à educação -, os formuladores de políticas públicas logo descobriram que, sem essas alternativas claras, estavam limitados a alguma variação dos velhos modelos a que antes se opunham.

Vou resumir meu argumento até aqui: ao mudar de um modelo tecnicista de instrução, associado com as correntes pioneiras da teoria do currículo, para uma crítica ideológica, a teoria do currículo perdeu (ou está perdendo rapidamente) seu objeto fundamental - o que se ensina e se aprende na escola. Sem dúvida, como resultado, perde seu papel específico nos estudos sobre educação. Essa 'perda do objeto' - a especificidade das escolas - teve duas consequências. Primeiro, abriu a porta da teoria do currículo para um amplo leque de pesquisadores dos campos de Filosofia, Literatura e Estudos Culturais, que levantam importantes questões sobre cultura e identidade na sociedade moderna, mas têm pouco a dizer especificamente sobre o currículo

importância de seu trabalho inicial só foi plenamente reconhecida mais recentemente (MOORE, 2004; MULLER, 2000; WHEELAHAN, 2010; YOUNG, 2008), em parte por inspiração de seu artigo sobre as estruturas do conhecimento (BERNSTEIN, 1999), escrito já no fim de sua vida. 
escolar. A segunda consequência é que os governos e os elaboradores de currículo - pelo menos no Reino Unido - prestam cada vez menos atenção aos teóricos do currículo como especialistas no campo do currículo. Isso pode ser um reflexo direto do desacordo entre formuladores de políticas públicas e acadêmicos, mas suspeito que seja também uma consequência da renúncia dos teóricos do currículo ao seu papel específico de especialistas. É fácil lamentar as forças do neoliberalismo. Às vezes, os acadêmicos se sentem muito confortáveis criticando os governos por suas políticas; no entanto, dada a renúncia da teoria do currículo ao seu objeto, devemos assumir pelo menos parte da culpa. Apesar da negligência dos pesquisadores da educação com o que é ensinado nas escolas e com o porquê de tantos alunos aprenderem tão pouco, essas questões não vão desaparecer e, em princípio, é a teoria do currículo que está na melhor posição para abordá-las. 0 desenvolvimento de uma teoria mais adequada, portanto, é uma grande tarefa para a qual este artigo pretende contribuir.

\section{AS ORIGENS DA CRISE DA TEORIA DO CURRÍCULO}

Por que, então, surgiu esta crise da teoria do currículo? Proponho três razões. Em primeiro lugar, como resultado da análise feita até aqui, está a desconfiança na especialização como fonte primária de novo conhecimento em qualquer campo - nesse caso, pondero que os estudos da Educação não são uma exceção. Tanto a crítica inglesa da herança elitista da 'educação liberal' (WILLIAMS, 1961) como a crítica estadunidense dos limitados modelos instrucionais referiam-se ao questionamento das premissas desses modelos sobre o conhecimento, considerado como algo estático e dado. No entanto, nenhuma das duas críticas tinha sua própria teoria do conhecimento (e, portanto, teoria do currículo), que levasse a uma visão das diferentes formas que o conhecimento poderia assumir no currículo. Portanto, afastaram esse campo do foco teórico sobre as diferentes formas de currículo para um foco político relacionado a questões de poder, política e, como no caso dos trabalhos de Pinar e outros, questões de identidade. No entanto, um foco no currículo como "a imposição arbitrária da cultura dominante”, nos termos de Bourdieu (BOURDIEU; PASSERON, 1990, p. 22), não faz avançar o nosso conhecimento das alternativas curriculares. Há um lugar para teorias sobre a luta pelo poder em campos intelectuais do tipo que Bourdieu inspirou, mas, sem abordar os limites da arbitrariedade inevitavelmente enfrentados por professores e elaboradores de currículo, essas teorias não tratam da difícil questão das alternativas curriculares na sociedade moderna. Para isso, é preciso que 
levemos o currículo a sério, como um objeto de prática e reflexão que opera dentro de dois tipos de restrições: de um lado, as do poder e da política; e, de outro, as restrições epistemológicas, segundo as quais, independentemente da distribuição do poder, a maneira pela qual o conhecimento é "selecionado, organizado e sequenciado" (para usar a conhecida frase de Bernstein) tem consequências para quem aprende e para o que se aprende na escola.

Como segunda razão, sugiro que a expansão massiva da escolarização levou, paradoxalmente, à perda de confiança em seu papel potencialmente emancipador. Sob a pressão do capitalismo global, isso se deve em parte ao crescente foco nos "meios" e não nos fins da educação. Desde a mais tenra infância, os alunos são estimulados a pensar no aprendizado em termos de seu futuro profissional ou ainda em termos de sua progressão escolar (do primário ao secundário ou do secundário ao superior). Esse foco nos 'meios' desloca a motivação dos alunos dos objetivos internos - o 'aprender por aprender', desprezado como elitista, mas crucial para o desenvolvimento intelectual de todos os alunos - para os objetivos externos, como a chance de um emprego no mercado de trabalho. Mas até os próprios estudos da Educação contribuíram para isso, especialmente certas tendências da Sociologia da Educação, que consideram que o papel das escolas na sociedade capitalista é a reprodução das relações de classe. Os intérpretes de Foucault (1977) também traçam paralelos entre escolas, hospícios e prisões. Não é que essas ideias sejam falsas ou que não ofereçam visões importantes sobre a escola. 0 problema é que elas podem facilmente se tornar descrições unidimensionais sobre 'para que serve a escola'. Trata-se de uma espécie de funcionalismo de esquerda que deixa muito pouco espaço para considerar as oportunidades de aprendizado que a escolarização pode oferecer a todos os alunos, o que soa menos "combativo" politicamente, mas nem por isso é menos importante. As disciplinas escolares, como a Física e a História, sempre oferecem possibilidades contraditórias. Para aprender, os alunos precisam seguir regras e sequências que são estabelecidas externamente e que podem ser percebidas como experiências impostas e até alienantes; por outro lado, com um professor bem qualificado, é seguindo essas regras que os alunos têm acesso a alternativas e a uma percepção mais ampla de suas próprias capacidades. Esta tensão entre 'obediência às regras' e 'avançar para além delas' perdeu-se na teoria do currículo, que despreza tais regras como simples expressões de poder ou de ideologia, ou, de forma igualmente enganosa, numa teoria que vê como 'meramente acadêmico' o aprendizado de qualquer coisa que não produza benefícios econômicos em curto prazo. 
A terceira razão para a crise na teoria do currículo que eu gostaria de sugerir é a aceitação cada vez maior, entre pesquisadores do campo da Educação, da ideia de que o conhecimento não tem qualquer significado ou validade intrínsecos. Resulta dessa visão que a questão enfrentada pelos professores fica limitada à pergunta ‘Este currículo faz sentido para os meus alunos?', em vez de 'Quais sentidos se abrirão para os meus alunos com este currículo?' ou 'Será que este currículo leva os meus alunos para além da experiência deles e permite que vislumbrem alternativas com alguma base no mundo real?'

Colegas meus na universidade, que convivem com professores em formação, relatam algo parecido com um 'medo do conhecimento' nas escolas que supervisionam - o conhecimento ou não é mencionado ou é visto como algo intimidador e dominador. Em consequência, se os teóricos do currículo não têm, eles mesmos, uma teoria do conhecimento, não é nenhuma surpresa que os professores interpretem as expressões de resistência cultural dos alunos como uma celebração de suas identidades e de seus significados subjetivos. Isso tem levado a uma abordagem psicologizante da identidade, que pensa o aluno como ser individual e não como ser social (ECCLESTONE; HAYES, 2009), ou a uma politização romântica de algum tipo de pedagogia crítica. Em primeiro lugar, essas abordagens negligenciam o fato de que os professores não podem escapar do elemento instrucional inerente ao seu papel. Os pais matriculam as crianças na escola com a expectativa de que elas adquiram o conhecimento especializado a que não têm acesso em casa. Em segundo lugar, essas abordagens falham em reconhecer que, embora o conhecimento possa ser percebido como opressivo e alienante, essa não é uma propriedade do próprio conhecimento. Uma pedagogia adequada, que possa comprometer o aprendiz em uma relação com o conhecimento (CHARLOT, 2012), pode ter consequências opostas, ou seja, pode libertar o aluno para novas formas de pensar e até para pensar o 'impensado'. Concluo que a teoria do currículo e, portanto, o próprio currículo precisa partir não do aluno como um aprendiz, mas sim do direito ou do acesso do aluno ao conhecimento. A teoria do currículo precisa de uma teoria do conhecimento (YOUNG, 2012) se pretende analisar e criticar os currículos existentes e explorar as diferentes formas que eles podem ter. Os teóricos do currículo não fazem os currículos; mas podem, pelo menos, ampliar as possibilidades disponíveis para os elaboradores de currículo.

Minha disciplina (a Sociologia da Educação e, mais especificamente, a Sociologia do Currículo) e meu próprio trabalho inicial perderam muito tempo na questão política: quem define a base de conhecimento do currículo? 
Embora seja uma questão importante, ela me levou a negligenciar a questão do próprio conhecimento e do que seria um currículo se seu objetivo fosse o 'direito ao conhecimento'.

\section{PREmissas para uma abordagem do CURRículo COM baSe no CONHECIMENTO}

O modelo de teoria do currículo que vou delinear é uma tentativa inicial de abordar esta questão: 'Qual é o conhecimento a que os alunos têm direito?' Antes disso, vou descrever brevemente minhas premissas, que dão forma tanto a este modelo quanto à maneira pela qual abordo a questão do conhecimento no currículo.

- Em todos os campos de pesquisa, há um conhecimento melhor, mais confiável, mais próximo da verdade sobre o mundo em que vivemos e sobre o que significa ser humano. Ao mesmo tempo, esse conhecimento não é estático nem dado; é sempre falível e pode ser desafiado. A dificuldade colocada por esta afirmação epistemológica é a de manter juntas essas duas ideias: 'há um conhecimento melhor' e 'esse conhecimento é falível'. Em qualquer comunidade acadêmica especializada, a falibilidade não quer dizer que 'vale tudo', mas sim que há regras e conceitos que sempre deixam algumas questões em aberto. Isso significa que, para experimentar a falibilidade do conhecimento, você precisa fazer parte da comunidade em questão ou estar envolvido com ela. As Ciências Naturais e as Ciências Sociais ou Humanas apresentam diferentes perspectivas com relação a isso. Na escola e mesmo na graduação, os alunos de Ciências Naturais precisam 'confiar’ na ideia da falibilidade, já que eles não sabem o suficiente de Matemática para reconhecer este conhecimento como 'falível', exceto no caso da Estatística. Já nas Ciências Sociais ou Humanas, quase não há acordo entre os especialistas sobre quais são as regras e os conceitos-chave da área. No entanto, mesmo nesses campos, é provável que haja certo grau de acordo no espectro de significados que seriam reconhecidos como abertos ao debate e, portanto, falíveis. É, porém, a esse conhecimento que eu me refiro como 'conhecimento poderoso', por mais que varie o conceito de falibilidade em cada campo.

O conhecimento poderoso tem duas características-chave e as duas se expressam sob a forma de fronteiras. 
- Ele é especializado, tanto na maneira como é produzido (em cursos, seminários e laboratórios) quanto na maneira como é transmitido (em escolas, faculdades e universidades), e essa especialização se expressa na fronteira entre áreas de conhecimento e disciplinas escolares que definem seu foco e seus objetos de estudo. Em outras palavras, não me refiro ao conhecimento geral. Isso não significa que os limites sejam fixos e imutáveis. No entanto, significa que o aprendizado e a pesquisa interdisciplinar dependem do conhecimento baseado nas áreas disciplinares.

- Ele é diferente das experiências que os alunos levam para a escola ou que os estudantes mais velhos levam para a faculdade ou a universidade. Essa diferença expressa-se nos limites conceituais entre o conhecimento cotidiano e o escolar.

Essas características do ‘conhecimento poderoso’ não estão restritas às áreas de conhecimento e disciplinas STEM (sigla em inglês para Ciência, Tecnologia, Engenharia e Matemática), como são conhecidas na Inglaterra, ainda que essas áreas de conhecimento e disciplinas expressem de maneira menos ambígua as características do conhecimento poderoso (YOUNG; MULLER, 2013). Embora não seja conhecimento geral, o conhecimento poderoso tem capacidades generalizantes. 0 conceito se aplica a:

- Ética - Por exemplo, o famoso princípio de Kant ('trate cada um como um fim em si mesmo e não como um meio para seus fins') é 'poderoso' não porque explique ou preveja, mas porque está tão próximo quanto possível de ser um princípio generalizável (ou universal) sobre como os seres humanos devem tratar os outros. Princípios quase idênticos podem ser encontrados em outras grandes obras de Filosofia, como as de Confúcio.

- Literatura e Artes - Grandes obras de arte são 'poderosas' porque tratam de emoções como culpa, remorso, pesar, responsabilidade e alegria, que são emoções vividas em contextos particulares, mas comuns a todos os seres humanos.

- História, Geografia e Ciências Sociais.

Em toda área do conhecimento há aqueles que se comprometem com o objetivo de buscar as melhores e mais confiáveis descrições dos fenômenos, assim como com a ideia de que existem regras e conceitos compartilhados. Também acreditam que o novo conhecimento se constrói a partir do conhecimento acumulado no passado, mesmo quando esse conhecimento tenha sido 
rejeitado, como no caso da maior parte da arte e da música modernas. Por outro lado, os fenômenos que preocupam esse campo são diferentes daqueles das Ciências Naturais. Não apenas seus métodos e conceitos são diferentes, mas eles inevitavelmente não gozam da mesma confiabilidade.

Eu parto do princípio de que a pergunta do currículo 'qual conhecimento?' deva ser tanto uma questão epistemológica - que define o que constitui o direito de aprendizado dos alunos em diferentes etapas e em diferentes campos de especialidade - quanto uma questão de justiça social, a saber, o direito ao conhecimento para todos os alunos, ainda que eles o rejeitem ou o considerem difícil. Se certo conhecimento é 'melhor', como podemos negá-lo a todos os alunos? Como podemos entregar um 'conhecimento sem poder' de fato, como fazemos na Inglaterra com alunos a partir dos 14 ou 16 anos?

\section{UMA ABORDAGEM DO CURRÍCULO BASEADO NO CONHECIMENTO}

Com essas premissas em mente, passo, nesta seção, aos princípios fundamentais que devem ser levados em conta na elaboração de um currículo baseado no conhecimento. Entre eles:

\subsection{Sua forma de especialização}

A partir de minha premissa de que o 'conhecimento poderoso' é especializado, resulta que a especialização no currículo universitário adquire a forma das fronteiras entre as áreas de conhecimento e que tais fronteiras são definidas por conceitos e regras para inclusão/exclusão, inferência e argumentação, e pelo sequenciamento dos conceitos. Os currículos escolares, por outro lado, têm objetivos pedagógicos, não de pesquisa. Tomam a forma de disciplinas, que são 'recontextualizadas' a partir das áreas de conhecimento.

A recontextualização, nesse sentido, significa (nos termos de Bernstein) seleção, organização e sequenciamento dos conteúdos, que levem em consideração tanto a coerência interna do conhecimento disciplinar quanto os limites do que pode ser aprendido por alunos em diferentes etapas de seu desenvolvimento. Em outras palavras, enquanto pesquisadores e professores universitários são limitados principalmente por critérios epistêmicos, os professores de escolas de educação básica também precisam levar em conta critérios pedagógicos e seu conhecimento das capacidades, experiência (e potencial) dos alunos. Essa é uma diferença estrutural e de sequenciamento, não de conteúdo. Os conceitos de Física ensinados na escola são sempre casos 
específicos dos conceitos da própria Física (por exemplo: um aluno aprenderá na escola que 'massa = força/aceleração' e, na universidade, aprenderá que ' $m a s s a=$ energia/velocidade da luz (ao quadrado), mas o primeiro conceito é um caso especial do segundo). A maneira de fazer a recontextualização vai variar muito nas diferentes disciplinas e áreas de conhecimento. Além disso, uma abordagem baseada na disciplina ou na área de conhecimento não impede os alunos de ganhar confiança suficiente para desafiar as fronteiras dessa disciplina ou área de conhecimento.

\subsection{A relação entre um currículo nacional e os currículos de cada escola}

Um currículo nacional deveria ser elaborado em colaboração estreita com os especialistas nas disciplinas e se limitar a conceitos-chave de cada disciplina. Esse alcance do currículo nacional garante autonomia para cada escola e para os professores especialistas em cada disciplina, e leva em conta que as escolas têm diferentes recursos culturais, histórias e contextos (por exemplo, escolas urbanas ou rurais). Ao mesmo tempo, garante uma base comum de conhecimento para todos os alunos, já que alguns podem mudar de escola.

\subsection{A diferença entre conhecimento especializado (currículo) e conhecimento cotidiano}

O conhecimento escolar (em outras palavras, o currículo) e o conhecimento cotidiano são constituídos por conceitos que diferem tanto em sua estrutura como em seu propósito. Os conceitos do cotidiano, que as crianças adquirem enquanto crescem, capacitam-nas a dar sentido ao mundo ao seu redor. Apesar de serem conceitos que servem apenas para contextos específicos, eles são flexíveis e adaptáveis a novos contextos e novas experiências. A experiência, nesse sentido, pode ser entendida como a aquisição de mais e mais conceitos que servem para contextos específicos. No entanto, a coerência desse conhecimento do dia a dia está vinculada a contextos particulares e, sem a oportunidade para se engajar com conceitos de um currículo baseado em disciplinas, o entendimento das crianças fica inevitavelmente limitado a esses contextos específicos e suas experiências cotidianas. Por outro lado, os conceitos associados a um currículo baseado em disciplinas não estão ligados a contextos específicos e sim conectados uns aos outros, assim como às teorias subjacentes de cada uma das disciplinas, legitimadas por sua comunidade de especialistas. É por conta dessa diferença de estrutura que os alunos que têm acesso a esses conceitos são capazes de generalizar 
para além de sua experiência. Além disso, essa estrutura do conhecimento especializado provê a lógica educacional para o currículo e suas ligações com os propósitos mais abrangentes da escolarização. Eis um exemplo que ilustra este conceito simples, porém abstrato:

Os alunos vivem numa cidade como Londres - eles conhecem a parte da cidade onde moram, os policiais e tudo mais. Este é um exemplo do conhecimento não escolar que os alunos trazem para a escola - será diferente para cada aluno e limitado às experiências deles ao crescer. Adquirir esse conhecimento não depende de ir à escola. Em algum momento, porém, os alunos vão encontrar o professor de Geografia. Professores de Geografia têm um conhecimento muito diferente sobre as cidades, que tem a ver com o quanto elas diferem entre si, a história de cada uma e como elas mudam. Isso é conhecimento escolar - neste caso, o conhecimento conceitual da Geografia -, a cidade é um exemplo de um conceito geográfico. Não substitui a experiência cotidiana do aluno; estende essa experiência e possibilita ao aluno generalizar a partir dela. Outros exemplos podem ser tomados da Literatura ou da História. No caso das Ciências, os alunos provavelmente chegam à escola com algum conhecimento do mundo material e natural. Nas aulas de

Ciências, experimentos de laboratório desempenham o papel do mundo cotidiano, a partir do qual o aluno generaliza. Os conceitos de Física e Química permitem-lhe pensar para além das atividades específicas desenvolvidas no laboratório (resumido de YOUNG, 2011).

\subsection{A diferença entre pedagogia e currículo}

Pedagogia $^{8}$, como a entendo neste artigo, refere-se ao que os professores fazem e levam os alunos a fazer; ainda que o ensino não seja apenas uma atividade prática (ou um ofício, como afirmam alguns políticos ingleses). 0 ensino depende tanto do conhecimento que os professores têm sobre sua disciplina como do conhecimento que têm sobre cada aluno e sobre como eles aprendem - e ainda do conhecimento que informa aquilo que os professores pedem aos alunos que façam. Por outro lado, ainda que o currículo represente o conhecimento a que os alunos têm direito, ele não inclui as experiências dos alunos. Essas experiências prévias dos alunos são um recurso fundamental para o aprendizado, mas variam enormemente. Além disso, os alunos não vão à escola para aprender o que já sabem por experiência.

\subsection{Avaliação 'como diagnóstico ou como indutora do currículo'}

É importante distinguir entre a avaliação como diagnóstico do progresso do aluno - para os próprios alunos e para os professores, pais e governo - e a

8 Estou usando a expressão 'pedagogia' de maneira analítica e não descritiva, para me referir a práticas e teorias (em geral implícitas) nas quais se baseiam os professores. Em línguas latinas, como o português, isso pode levar a alguma confusão, já que o significado de pedagogia é quase equivalente ao termo 'educação'. 
avaliação como indutora do currículo e da pedagogia. Os professores estão sendo cada vez mais pressionados para abandonar o papel diagnóstico da avaliação e para focar em seu caráter de responsabilização, indutor de políticas e currículo.

\section{IMPLICAÇÕES PRÁTICAS - UM EXEMPLO}

Há 18 meses venho conversando com a diretora de uma grande escola de ensino médio na Inglaterra (com uma equipe de mais de 80 pessoas). Inicialmente, as conversas surgiram do fato de ela ter lido meu livro (YOUNG, 2008) e me levaram a tratar algumas das questões abordadas neste artigo. Recentemente, ela escreveu um manifesto para todos os funcionários da escola sob o título "Uma escola voltada para o conhecimento" (ver Anexo). Não digo que suas ideias derivem diretamente de nossas conversas. Mas acho que seu manifesto ilustra como ideias quase sempre consideradas abstratas podem se constituir em apoio para um diretor que busca liderar a construção curricular, e como questões difíceis e muitas vezes abstratas da Sociologia do Currículo podem ser expressas de forma acessivel a não especialistas. Seu próximo passo será pedir aos coordenadores pedagógicos que comentem o manifesto do ponto de vista de cada uma das disciplinas.

\section{OBJEÇÕES À ABORDAGEM BASEADA NO CONHECIMENTO}

A abordagem do currículo que proponho tem sido duramente rejeitada na Inglaterra, não apenas por professores, mas por muitos acadêmicos e pela maioria daqueles que se consideram politicamente 'de esquerda'. Quero concluir este artigo, portanto, com considerações sobre as três objeções mais frequentes que tenho enfrentado como teórico do currículo no Reino Unido, ao defender o currículo baseado no conhecimento.

Acho útil distinguir os três tipos de objeção - a de ordem prática, a epistemológica e a política -, ainda que seja evidente e inevitável a sobreposição desses três tipos de objeções.

\subsection{Objeções de ordem prática}

Mesmo em países desenvolvidos e com recursos relativamente altos, como o Reino Unido, uma porcentagem significativa dos alunos de ensino médio não consegue atingir um nível educacional adequado aos 16 anos de idade. Sem 
mudanças na formação dos professores e nos recursos destinados à equipe escolar, este modelo de currículo baseado em conhecimento que estou propondo levaria certamente ao aumento daquela porcentagem e encorajaria ainda mais o desinteresse pela escola e o abandono escolar.

Esta é a razão pela qual alguns acadêmicos e muitos professores acreditam que um currículo assim não seria factível para todos os alunos, pois esta abordagem não reconheceria as reais dificuldades que os professores enfrentariam para engajar mais do que uma minoria de alunos nesse currículo. Argumentam que a maioria dos alunos precisa de um currículo mais relacionado aos seus interesses e capacidades. Por outro lado, embora haja evidências de que os programas que focam nos interesses imediatos dos alunos podem deixá-los mais contentes com a escola, tais programas negamlhes acesso ao próprio conhecimento de que eles precisam para progredir nos estudos ou para ter uma chance razoável no mercado de trabalho. Nas sociedades capitalistas ocidentais, este é o dilema prático inescapável do ensino médio de massa e que não é enfrentado pelos programas orientados às comunidades vulneráveis ou ao trabalho. O que tais programas fazem, porém, é mascarar o problema do fracasso escolar e diminuir a probabilidade de que esse problema seja abordado em suas origens, que, de fato, não estão nas escolas, mas nas desigualdades mais amplas da sociedade. Como direi mais adiante, isso nos leva a questões políticas, para além do currículo. 0 dilema prático é mais uma crítica a um tipo de sociedade do que a uma teoria do currículo.

\subsection{Objeções de ordem epistemológica}

A abordagem do currículo que parte do conhecimento é criticada de duas maneiras bem distintas por alguns acadêmicos. Os que endossam teorias do conhecimento pós-modernistas e pós-estruturalistas afirmam que todo conhecimento tem, inevitavelmente, 'um ponto de vista'. Segue-se que identificar certo conhecimento como 'poderoso' é quase a mesma coisa que aceitar as definições dominantes de conhecimento que se encontram nas escolas de elite ${ }^{9}$. Dessa perspectiva, novamente, a abordagem voltada

9 Já disse antes que esta perspectiva vê o currículo como expressão do 'conhecimento dos poderosos'; em outras palavras, aqueles em posição de poder definem o currículo para as escolas de elite de forma a ajustá-lo às necessidades de seus filhos e, na prática - senão de maneira explicitamente intencional -, para discriminar contra o resto. Esse foco nas escolas de elite é importante, mas é necessário distinguir as escolas de elite dos currículos de elite. As primeiras focam no acesso desigual, enquanto os currículos de elite explicitam que o próprio conhecimento pode ser reconstruído - que, por 
ao conhecimento é ideológica. Afirma-se que, como todo conhecimento é arbitrário, uma abordagem voltada ao conhecimento não passa da imposição de interesses específicos. Os interesses e preferências dos alunos constituem, dessa perspectiva, um critério curricular tão bom quanto qualquer outro. Como indiquei antes, negar a universalidade e a possibilidade de democratização do 'conhecimento poderoso' significa que a teoria do currículo só pode exercer a crítica. A única alternativa que essa perspectiva oferece aos professores é que eles ajudem os alunos a encontrar algum sentido para suas vidas, independentemente do quão limitadas sejam essas possibilidades.

A objeção epistemológica feita por alguns filósofos (por exemplo, WHITE, 2012) ao currículo baseado no conhecimento é que as 'disciplinas escolares' estão desatualizadas e são inapropriadas para um mundo em que o conhecimento está mudando tão rapidamente. No entanto, isso confunde conteúdo com estrutura do currículo (YOUNG, 2012). 0 fato de que alunos de ensino médio na Inglaterra de 1870 estudavam Física e História e de que ainda estudem não significa que os conteúdos tenham permanecido os mesmos. As disciplinas são recursos educacionais, que tópicos e temas interdisciplinares (como o meio ambiente) não podem nunca ser, por mais importantes que sejam. Disciplinas são:

- Fontes de estabilidade para as escolas, os alunos e os professores. Isso é importante, já que um dos papéis da escola é 'transmitir' o conhecimento acumulado por gerações anteriores.

- São fontes de coerência nacional (e internacional). As famílias mudam e os alunos vão a uma nova escola no mesmo país ou em outro país. As disciplinas dão alguma garantia (algumas mais do que outras) de que o aluno poderá continuar e avançar em seus estudos com alunos de faixa etária similar em outra escola. Alunos cujas aulas não se estruturam em disciplinas, mas em temas e tópicos, muitas vezes acabam repetindo as mesmas coisas ano após ano, sem nenhuma sensação de progresso.

- Disciplinas são fontes de identidade tanto para os alunos como para os professores. Para os professores, elas foram desenvolvidas por associações profissionais de especialistas (de professores de Matemática, por exemplo), onde podem compartilhar e discutir novas abordagens. Para os alunos, o papel das disciplinas é análogo, mas diferente. No início, eles entram no que muitos vão considerar daquela aprendida na escola privada. Vou voltar a esse ponto na conclusão. Trata-se de um dilema não resolvido por nenhuma das abordagens socioconstrutivistas do currículo. 
um estranho mundo do currículo; a experiência anterior deles não era baseada em disciplinas. No entanto, disciplinas com regras e fronteiras claras oferecem-lhes a oportunidade de desenvolver novas identidades, como parte de novas comunidades de alunos, e, assim, tornarem-se prontos para avançar numa disciplina e, em alguns casos, até para desafiar essas fronteiras.

- Disciplinas, como já disse, são recontextualizadas a partir das áreas de conhecimento que são a fonte primária da sociedade para a produção de novo conhecimento. 0 elo entre disciplinas e áreas de conhecimento é a melhor garantia que temos de que o conhecimento adquirido pelos alunos na escola não depende exclusivamente da autoridade do professor-indivíduo, mas sim do professor como membro de uma comunidade de especialistas em sua disciplina.

\subsection{Objeções de ordem política}

No Reino Unido, as propostas curriculares do Governo de Coalizão (DFE ${ }^{10}+$ 2011) dão uma ênfase considerável a um específico e reduzido leque de disciplinas, de fato limitando a escolha tanto para escolas como para alunos. Essas propostas, como indiquei antes, encontraram a oposição de literalmente todos os que estão ‘à esquerda'. São vistas como elitistas e como promotoras da injustiça social e de desigualdades ainda maiores. Como os pós-estruturalistas que discuti antes, esses críticos aceitam, implicitamente, o argumento relativista de que não existe um 'conhecimento poderoso' representado pelas disciplinas que seja um direito de todos os alunos. Eles partem da premissa de que o 'acesso ao conhecimento disciplinar' não deve ser prioridade para um terço dos alunos entre 14 e 16 anos, uma vez que esses alunos não estariam interessados ou achariam o conteúdo muito difícil, ou ainda que isso exigiria esforços impossíveis por parte dos professores. A lição perturbadora que tiro dessa objeção é que muitos desses críticos racionalizam, de alguma forma, sua resistência à questão do conhecimento; ou talvez estejam relutantes em aceitar que, para todos os efeitos, as limitações epistemológicas são inescapáveis.

O dilema é mais fácil para os 'de direita', já que não acreditam sequer na possibilidade de uma redução progressiva das desigualdades. Eles até aceitam uma versão do 'conhecimento poderoso' como base do currículo, mas atribuem inteiramente às escolhas individuais dos alunos os níveis de fracasso a que essa versão possa levar (eles não estudam o suficiente ou seus 10 + DFE é a sigla em inglês do Ministério da Educação do Reino Unido. [N. da T.] 
pais não os apoiam na escola). Moral e politicamente, não acho sustentável o argumento que repousa na escolha individual, já que as possibilidades de escolha não são distribuídas igualmente. No entanto, isso não ajuda a resolver o dilema enfrentado pelos 'de esquerda', que estão comprometidos com a igualdade.

Meu próprio ponto de vista é que o currículo não pode, sozinho, reduzir significativamente as desigualdades educacionais. Em sociedades capitalistas como as nossas, as escolas reproduzem essas desigualdades de maneira acentuada em alguns países e menos acentuada em outros. No entanto, a redução das desigualdades sociais e o estabelecimento de uma sociedade mais igualitária é principalmente uma tarefa política e não uma tarefa educacional. Na Inglaterra, uma fonte fundamental da desigualdade educacional é a oportunidade que famílias ricas têm de comprar uma educação "melhor"11 para seus filhos em escolas privadas que chegam a custar mais de 30 mil libras esterlinas por ano. É um triste comentário sobre o Labor Party++, principal partido de esquerda, que, nas duas vezes em que teve maioria no Parlamento (em 1945 e em 1997), tenha evitado a 'questão da escola privada'. No entanto, este é um problema político, não educacional. Só é uma tarefa dos educadores em nosso papel de cidadãos; há uma real divisão do trabalho. Já não estou convencido, como estava nos anos 1970, de que é importante ver tudo como político. Posso ter opiniões sobre a escola privada, mas não tenho espaço político para agir a partir dessas opiniões; o Labor Party está muito longe de tratar da questão e já não há sequer a possibilidade de uma esquerda socialista ou alguma ideia de que tipo de alternativa ela poderia oferecer. Para nós, os teóricos do currículo, e para nossos colegas nas escolas, a tarefa, independentemente de nossa visão política como cidadãos, é desenvolver princípios curriculares que maximizem as chances de que todos os alunos tenham acesso epistêmico (MORROW, 2008) - ou acesso ao melhor conhecimento disponível em qualquer campo de estudo pelo qual se interessem. Negar acesso a esse conhecimento a alguns alunos, porque para eles seria muito difícil, é como negar o equivalente ao nosso juramento de Hipócrates - oferecer-lhes o 'melhor conhecimento' que pudermos. Pelo menos um currículo baseado no conhecimento vai destacar, em vez de mascarar, as desigualdades de nossa sociedade, como invariavelmente fazem os chamados programas pré-vocacionais. A mensagem política do currículo baseado no conhecimento é que as desigualdades na distribuição de qualquer tipo de recurso devem ser reduzidas se queremos ampliar as

11 Ou pelo menos uma educação que dê a seus filhos uma chance de conseguir boas notas e entrar em uma universidade de primeira linha.

++ Literalmente, 'Partido do Trabalho'. [N. da T.] 
oportunidades educacionais - e esta é, na expressão contemporânea, 'a pergunta que não quer calar’. Entrementes, um currículo melhor, apoiado por bons professores que acreditem nele, continua sendo a mais alta prioridade. A luta pela escolarização sempre foi uma luta pelo conhecimento - e este deve ser o foco do debate curricular atual.

Os teóricos do currículo são, como tenho argumentado, os especialistas educacionais em conhecimento e é por isso que lançamos mão de Sociologia, Filosofia e, às vezes, Psicologia. Os partidos políticos e os governos precisam do nosso conhecimento especializado, mesmo que não o reconheçam, se pretendem que suas políticas curriculares reflitam ideias como educação e oportunidades iguais para todos. 


\section{Overcoming the crisis in curriculum theory: a knowledge-based approach}

Abstract: This paper begins by identifying what it sees as the current crisis in curriculum theory. Following a brief history of the field, it argues that recent developments have led to it losing its object--what is taught and learned in school--and its distinctive role in the educational sciences. Arising from this brief account of the origins and nature of this 'crisis', the paper argues that curriculum theory must begin not from the learner but from the learner's entitlement to knowledge. It then develops a framework for approaching the curriculum based on this assumption which is illustrated by an example of how the Head Teacher of a large secondary school in England used these ideas. Finally, it examines three widely held criticisms of the knowledge-based approach developed here and the issues that they raise.

Keywords: Curriculum. Knowledge. Specialization. Subjects. 


\section{REFERÊNCIAS}

APPLE, M. Ideology and Curriculum. Londres: Routledge/Falmer, 2004 (1975). BERNSTEIN, B. Class Codes and Control: volume 1. Londres: Routledge, 1971. - Vertical and horizontal discourse: an essay. British Journal of

Sociology of Education, v. 20, n. 2, p. 157-173, 1999.

BOBBITT, F. The Curriculum. Nova York: Houghton Mifflin, 1918.

BOURDIEU, P.; PASSERON, J. C. Reproduction in Education, Society and Culture. Londres: Sage, 1990.

CALLAGHAN, R. Education and the Cult of Efficiency. Chicago: University Press, 1964.

CHARLOT, B. School and pupil's work. In: LAUDER, H.; YOUNG, M.; DANIELS, $\mathrm{H}$. et al. (Eds.). Educating for the Knowledge Economy? Critical Perspectives. Londres: Routledge, 2012, p. 211-223.

DENG, Z.; LUKE, A. Subject matter; defining and theorizing school subjects. In: CONNELLY, F. M.; HE, M. F.; PHILLION, J. (Eds.). Sage Handbook or Curriculum and Instruction. Thousand Oaks: Sage, 2008, p. 66-87.

DFE. Disponível em: 〈http://www.education.gov.uk/schools/ teachingandlearning/curriculum/nationalcurriculum». Acesso em: 2011.

DURKHEIM, E. Elementary Forms of Religious Life. Londres: Allen and Unwin, 1915.

. Pragmatism and Sociology. Cambridge: Cambridge University Press, 1983.

ECCLESTONE, K.; HAYES, D. The Dangerous Rise of Therapeutic Education. Londres: Routledge, 2009.

EGAN, K. Getting it Wrong from the Beginning: Our Progressivist Inheritance from Herbert Spencer, John Dewey, and Jean Piaget. Nova York: Yale University Press, 2004.

FOUCAULT, M. Discipline and Punish. Londres: Allen Lane, 1977.

GIROUX, H. Theory and Resistance in Education. Nova York: Bergin and Hervey, 1983. 
GOODSON, I. School Subjects and Curriculum Change. Londres: Routledge/ Falmer, 1987.

HIRST, P.; PETERS, R. The Logic of Education. Londres: Routledge, 1970.

MCLAREN, P. An Introduction to Critical Pedagogy. Londres: Longman, 1995.

MEYER, J. School Knowledge for the Masses: World Models and National Primary Curricular Categories in the Twentieth Century. Londres: Falmer, 1992.

MOORE, R. Education and Society. Londres: Polity Press, 2004.

MORROW, W. Bounds of Democracy; Epistemological Access in Higher Education. Pretoria: HSRC Press, 2008.

MULLER, J. Reclaiming Knowledge. Londres: Falmer Press, 2000.

PINAR, W. Understanding Curriculum: An Introduction to the Study of Historical and Contemporary Curriculum Discourses. Nova York: Peter Lang, 1978.

WHEELAHAN, L. Why Knowledge Matters in the Curriculum: A Social Realist Argument. Londres: Routledge, 2010.

WHITE, J. Powerful knowledge: too weak a prop for the traditional curriculum. Disponível em: 〈http://www.newvisionsforeducation.org.uk/2012/05/14/ powerfulknowledge-too-weak-a-prop-for-the-traditional-curriculum/>. Acesso em: 2012.

WILLIAMS, R. The Long Revolution. Londres: Chatto and Windus, 1961.

YATES, L.; YOUNG, M. Editorial: globalisation, knowledge and the curriculum. European Journal of Education, v. 45, n. 1, p. 4-10, 2010.

YOUNG, M. Knowledge and Control. Londres: Collier Macmillan, 1971.

Bringing Knowledge Back In. Londres: Routledge, 2008.

. Curriculum theory and the problem of knowledge: a personal journey and an unfinished project. In: WAKS, L.; SHORT, E. (Eds.). Leaders in Curriculum Studies; Intellectual Self Portraits. Roterdã: Sense Publishers, 2009.

The future of education in a knowledge society: the radical case for a subject-based curriculum. Journal of the Pacific Circle. Consortium for Education, v. 22, n. 1, p. 21-32, 2011. 
An entitlement to powerful knowledge: a reply to John White. 2012. ; MULLER, J. Artigo inédito. 2013.

; WHITTY, G. Society, State and Schooling. Londres: Falmer Press, 1977. 


\section{ANEXO - UMA ESCOLA VOLTADA PARA O CONHECIMENTO}

No meio de grandes mudanças estruturais, lembremo-nos de nosso papel como educadores da sociedade e guardiões dos jovens. Se os Teachers' Standards (padrões docentes) são as expectativas com relação ao nosso profissionalismo, qual é o nosso propósito? Somos nós que oferecemos conhecimento compartilhado e poderoso às crianças do país. Esse conhecimento vem de séculos de aprendizado e das universidades e associações disciplinares. É poderoso porque habilita as crianças a interpretar e controlar o mundo; é compartilhado porque todas as nossas crianças deveriam ser expostas a ele. É justo e imparcial que seja assim. É injusto e parcial quando as crianças recebem conhecimento de má qualidade, que não consegue levá-los para além de sua experiência.

Aqui estão dez lembretes:

- 0 conhecimento vale por si mesmo. Diga isso às crianças: nunca se desculpe por elas terem de aprender alguma coisa.

- As escolas transmitem um conhecimento poderoso e compartilhado, em nome da sociedade. Ensinamos aquilo de que elas precisam para poder dar um sentido ao mundo e melhorá-lo.

- O conhecimento compartilhado e poderoso é verificado por meio de comunidades de intelectuais. Precisamos manter contato com universidades, com a pesquisa e com associações disciplinares.

- As crianças precisam do conhecimento poderoso para entender e interpretar o mundo. Sem ele, permanecem dependentes de quem o tem.

- 0 conhecimento poderoso é superior, em termos cognitivos, àquele necessário para a vida cotidiana. Ele transcende essa experiência cotidiana e liberta as crianças dela.

- O conhecimento compartilhado e poderoso habilita as crianças a se tornarem cidadãos ativos. Como adultos, poderão entender, cooperar e transformar o mundo juntas.

- O conhecimento compartilhado é um fundamento de uma sociedade justa e sustentável. Cidadãos educados juntos compartilham um entendimento do bem comum.

- É justo e imparcial que todas as crianças tenham acesso a esse conhecimento. 0 conhecimento poderoso abre portas: ele precisa estar disponível para todas as crianças.

- A aceitação da autoridade do adulto é um requisito para a comunicação 
do conhecimento compartilhado.

- A pedagogia liga a autoridade do adulto, o conhecimento poderoso e sua comunicação. Precisamos de profissionais de qualidade para conseguir isso para todas as nossas crianças. 